\title{
Complaint management in closed-loop supply chain and performance evaluation by using exergoeconomics
}

\author{
Guojun $\mathrm{Ji}^{*}$
}

\begin{abstract}
Complaint service management, aimed at improving customer satisfaction, provides important content for incorporation into studying a closed-loop supply chain. An analysis of the relationship between two provides the basis for probing the role of complaint management (CM) in the closed-loop supply chain to help it perform more efficiently and effectively through the application of advanced technologies. This paper considers how CM can be computed combining computer communication and information technologies. This computing process involves collection, evaluation and disposal. Using computer telephone integration technology, an integrated multi-channel system is designed; complaint and production evaluated through an intelligent decision support system; and CM processing system established to implement corresponding disposal which reflects the utility of CM. This research on the process of incorporating CM into our studies has significance for computing business service in the future. Based on exergoeconomics theory, the closed-loop supply chain is discussed, and the metric about "system negative environment effect" is introduced to system performance in terms of energy expenditures; a case study illustrates the efficacy of the process
\end{abstract}

Keywords: Exergoeconomics, Exergy, Closed-loop supply chain, Complaint management, Computer Telephone Integration system.

\section{Introduction}

Rapidly globalizing markets, production and distribution systems operating within complex and fluid capital markets have triggered exceptional economic and competitive pressures in national economies. Consequent microeconomic reform, deregulation and the corporatization and 
privatization of national market places have been no less significant and have further impacted on nation-wide, as well as international, global logistics systems so that change is now pervasive, urgent and transforming. For buyers of freight services, whether manufacturers, rural and primary producers or retail giants, the pressing need to control costs in supply chains has spawned numerous strategies within a broader supply chain management framework that seeks sophisticated levels of operational as well as corporate integration-and ideally, fully integrated corporate and intercorporate business processes. For sellers of freight services-traditional "transport" providers now best described as third party logistics providers or fourth party service providers. They provide the outsourcing service of reverse logistics to the companies, intervene between buyer or shipper and customer-the focus on value delivery in competitive markets and are underlying urgent attempts to expand control over freight activities and to capture an increased share of value over the entire movement chain. It is resulting in rapidly restructuring corporate and value delivery systems.

Therewith, over the last several years, changes in environmental laws and the new returns demands of market returns have raised the requirement for effective reverse logistics to a new level, reverse logistics issues are gaining justifiable popularity among society, governments and industry worldwide. They are mainly regulatory-driven in Europe, consumer-driven, market-driven and profit-driven in North America and in incipient stage in other parts of the world, including China, where both consumer awareness and globalization are likely to lead to greater economic, consumer and regulatory pressures in the coming future. Only very recently, some companies in consumer durables' and automobile sectors in China have introduced exchange offers to tap customers who already own such products. Presently, these returned products are either resold directly or after repair and refurbishment by firm franchisee/local remanufacturers in the seconds' market. They are not remanufactured or upgraded by original equipment manufacturers (OEMs). The Chinese society had been particularly price-sensitive and to a little extent quality sensitive-(quality for a given price) but not environment-sensitive in its buying and promotion behavior in past years. Therefore, reverse logistics has not received the desired attention and is generally carried out by the unorganized sector for some recyclable materials such as paper and metal. Also, manufacturers must deal with returns from retailers, the channels of distribution, or end customers with warranty issues. For instance, in 2005, the emitted cement tunnage's amount was more than two cement factories outputs, as reported by Chinese News. In 2001 there were about 40 million desktops and mobile Personal Computers sold. About 9 million (23\%) of these were sold through retail stores. The retailer experienced a return rate of about $10 \%$ or 900,000 Units. Each of these units is estimated to cost the retailer $\$ 40-\$ 50$ to process and ship back to the manufacturer or to dispose of the units. The manufacturers estimate that each return costs them about $\$ 500$ each. This adds up to a whopping $\$ 486$ million. Each return is taking the manufacturers from 4 to 12 weeks to fully process (Cruz, M., 2000). Returns are a small percentage of sales for the retailer or manufacturer, however, in high-volume environments like consumer goods and the cement product, this small percentage adds up to a large reverse logistics problem (Guojun Ji, 2006).

The term closed-loop supply chain has not appeared as such in the literature on supply chain and operations management until the beginning of this century. Several authors have spoken of 'reverse supply chains', a topic which was mainly discussed in practitioner circles (Morrell, A. L., 
2001). However, a clear definition of closed-loop supply chain only seems to have emerged thereafter. In their earlier work, the closed-loop supply chains for refillable containers, photocopier remanufacturing and the re-use of consumer electronics are discussed (Smith, V. M. and Keoleian, G. A., 2004). Probably the first contributors in designing a closed-loop supply chain were Thierry et al., (1995) with their model of an 'integrated supply chain'. This chain of companies has been defined as a supply chain, which comprises service, product recovery, and waste management activities. In this model, products return from the end-user to undergo a product recovery operation, such as re-use, repair, remanufacture or recycling. Thereafter, products are integrated back into the 'forward' supply chain. Closed-Loop Supply Chain Management includes processes and operations that can not be found in conventional supply chain management. Krikke et al., (2003) explain that a closed-loop supply chain consists of a forward and a reverse chain. Guide and Van Wassenhove (2003) further add that the additional activities of the reverse supply chain include product acquisition, reverse logistics, test, sort disposition, refurbishing as well as distribution and marketing. While there is a variety of theoretical considerations for conventional supply chain management, there is still a lack of a theory for closed-loop supply chain management, particularly with regard to the additional elements that the reverse supply chain incorporates.

In fact, closed-loop supply chain management has become an important strategy for enterprises and even countries to seize the global plateau. The industrial ecology issues such as 3Rs (reducing, reusing and recycling) strategies, cost-saving ecological ideas and programmes, green teams and so on are enjoying extensive popularity in society, government and industry, etc. On the other hand, the leading actors in today's markets have transformed from sellers to buyers, whether or not meet customers' individuation demands become an important factor to show enterprises' talents in the competitive environment. The information asymmetry between enterprises and customers, the complexity in the business environment, the diversity of customers' demands and so on, all indicate that customer complaint is unavoidable (Andreasen A.R., 1988). According to the modern organizational behavior theory, the viewpoint of complaint shows that the enterprise should admit customer complaint, even more advocates it. Customer complaint helps the enterprise win the customer again and provides the change to improve product (J.X. You et al, 2003). Therefore, enterprises in supply chain must take active efforts to treat customer complaint and manage it effectively. The complaint information such as the returned product coming from consumer is portion of the closed-loop supply chain; at the same time, complaint management (CM) in the closed-loop supply chain needs to be discussed. From the strategic view, CM is the crucial composing of the closed-loop supply chain strategy and an effective approach of the closedloop supply chain management. For example, CM can help organizations build customer loyalty and find new value-added etc. Nowadays, computer technology, communication technology and information technology are active and progressing aggressively. Those would give CM important stimulus and prompting to perform more efficiently and effectively.

The concept of exergy, a parameter in thermodynamics, was presented at first by Z. Rant in 1956. With several decades of development, the exergy analysis has become the basic theory and a useful tool in analyzing the energetic system and has obtained attention and wide application. Thermodynamics combined with economics results in exergoeconomics. The theory of exergetic cost is applied in design analysis and optimization, operation optimization and diagnostics, etc. 
Exergy has been proved to be suitable as a common quantifier of the sustainability of a system by Marc A. Rosen (2005) et al. Based on the traditional exergoeconomics theory, Shizhen Bai et al. (2005) introduced the environment effect factor as the measurement of supply chain system evaluation considered the sustenance of environment and resource. However, there are limitations in identification of the coefficient and no case study to support it.

In this paper, complaint service management, aimed at improving customer satisfaction, is an important content for closed-loop supply chain. By analyzing the relationships between complaint management and closed-loop supply chain, complaint management in the closed-loop supply chain is probed into. We take into consideration the process computing of CM by combining computer communication and information technologies. The process of CM includes collection, evaluation and disposal. Based on the computer telephone integration technology, an integration multi-channel collection routeway can be designed; the evaluation of complaint and production is supported by intelligent decision support systems. In accord with the different disposal countermeasures, the CM processing system is established to implement corresponding disposal, which reflects the utility of CM. Based on the exergoeconomics theory, the closed-loop supply chain is regarded as a huge energy system with the new view, and the sustainability of the closedloop supply chain system is discussed under the circumstance of exergoeconomics, and the metric about "system negative environment effect" is then introduced to measure the closed-loop supply chain system performance in the point of energy; a case study illustrates the efficacy of the process.

\section{Complaint management and closed-loop supply chain}

\subsection{CM is an important reason for closed-loop supply chain}

As a whole, reverse logistics can be classified by return and reclaim in closed-loop supply chains. Return is "push" logistics produced by all distributors or end customers; and reclaim driven by manufacturers is called "pull" logistics (M. Chouinard, et al., 2005). "Push" logistics mostly involves reverse-flowed products and information; customer complaint just aims at the product information feedback, not any government policy. In fact, any complaint may trigger reverse activities in closed-loop supply chain. When analyzing customer complaint information professionally, some bugs in product designing or production processes may be found out, hence enterprises in the closed-loop supply chain must recall those products initiatively, i.e., results in the "pull" reverse logistics. It is obvious that complaint management is an important reason for engendering reverse logistics in closed-loop supply chain, as shown in

\subsection{The significance of CM in the closed-loop supply chain management}

Information on customer complaints or feedback information, as well as product flow conversely are all closed-loop supply chain activities. Based on sufficient communication with 
customers, enterprises in closed-loop supply chain can implement reverse channel to collect the complaint information to track investigation and gather analysis the gathered data about client, product status, processing flow etc. In closed-loop supply chain management, reverse activities can be organized according to complaint management; those activities include: reuse, repair/repackage, return to supplier, resell, junk, recycle, renew and so on.

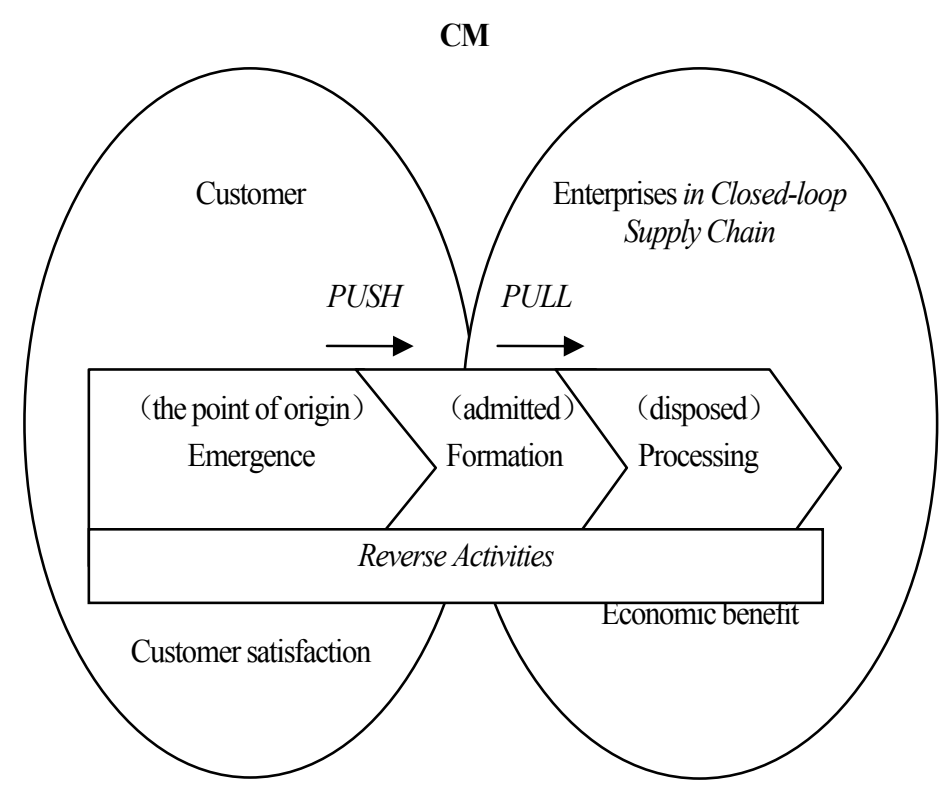

Figure 1. The formation of "push" and "pull" reverse logistics

\subsection{The objective of CM is based on customer satisfaction}

The objective of complaint management is to enhance customer satisfaction; this does not contradict the objective of the economic benefit in implementing closed-loop supply chain management. If enterprises in supply chain want to win customers, making customers satisfied is necessary. There is also need to provide better service after purchase, thus, the reverse activities become important sustentation. That is to say, the closed-loop supply chain strategy is of an important approach to meet customer demand. With growing customer satisfaction, public praise will prevail widely; then higher market possession and production profit will be received. On the other hand, from remanufacturing spoiled and rebuilding disused products, enterprises in supply chain can excavate more underlying value to increase incomes (D.S. Rogers, and R.S. TibbenLembke, 2001). 


\subsection{Process management of CM}

$\mathrm{CM}$ is one of the important items in closed-loop supply chain strategy; the process of CM should include three functions: collection, evaluation and disposal (Marisa P. de Brito, and R. Dekker, 2001), see

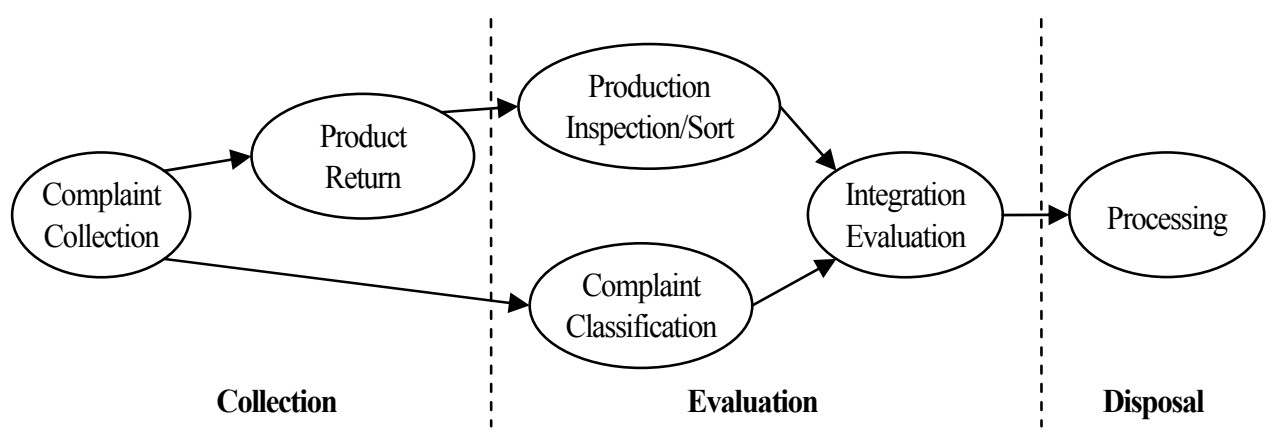

Figure 2. The process of CM

\subsubsection{Collection}

To capture complaint, the enterprise in closed-loop supply chain needs to lower "the threshold" to invite the voice of complaint. According to the customer complaint information, the organization collects the returned product dispersing in customers' hands. Those activities include collection, transport, and storage.

A convenient channel is very important to improve the response service to customers for the closed-loop supply chain. Traditionally, the complaint channels that the supply chain provides to customers are telephone, letter, fax, etc.; nowadays the Internet and wireless information technology are newly emerging field. These techniques have their own advantages. To maximize customer satisfaction, the integrated multi-channel service should be a good choice. Before the complete integration of the channels, let us consider a computer integration technique, the Computer Telephone Integration system (CTI). Generally speaking, the phonetic system is separate from the computer network system, but CTI technique can integrate the two functions together (X.Y. Shang, \& Guojun. Ji, 2006). A typical service process of CTI is represented in Figure 3.

(1) Customer-call-organization switch equipment. The switch equipment receives the key request service number via Automatic Number Identification (ANI) and Dialed Number Identification 


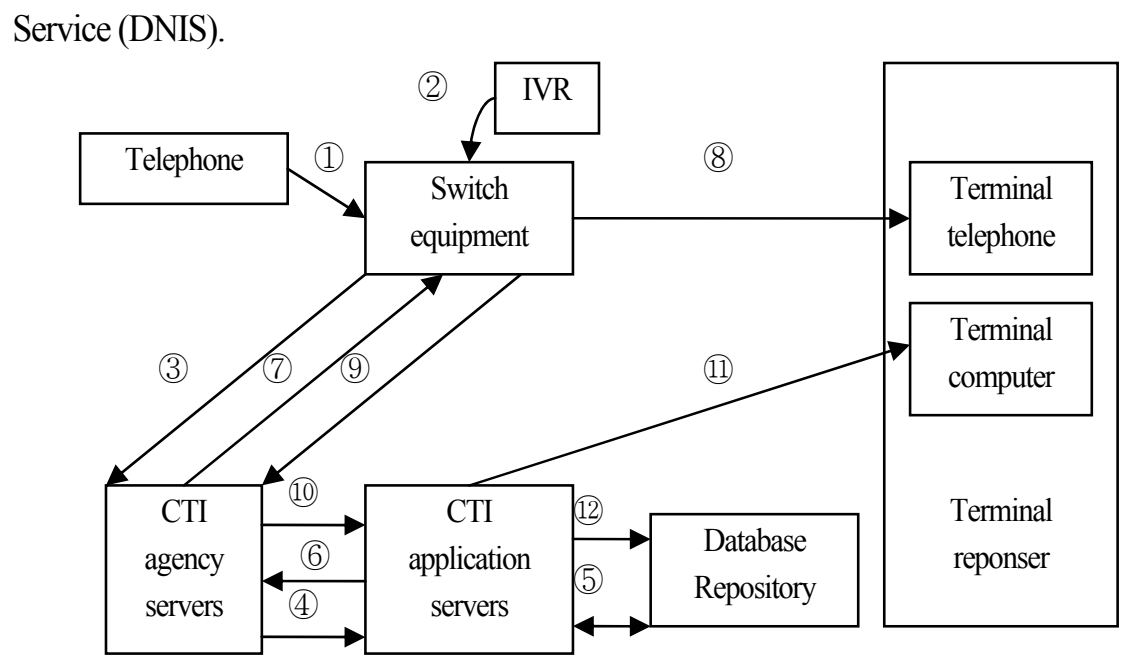

Figure 3. The CTI service process

(2) If Interactive Voice Response (IVR) equipment are available, the switch equipment will memorize the key-press information of customers automatically.

(3) The switch equipment transfers the numbers and key-press information from step (1) and step (2) to the CTI agency servers.

(4) The information format is transformed in the agency servers, then the information is sent to the CTI application servers.

(5) According to the input parameters, the CTI application servers will implement relevant logical operations, for example, search for the best responder in the database.

(6) Return the search result (the best responder) to the CTI agent servers.

(7) The CTI agent servers send the information of the best responder to the switch equipment.

(8) The communication is turned into the best responder by the switch equipment.

(9) After ending the communication, the switch equipment sends the end-of-exchange signal to the CTI agent servers.

(10) The success-of-exchange signal is transmitted from the CTI agent servers to the CTI application servers.

(11) The CTI application servers transmit the data information to the terminal responder, such as pop-upping the calling prompt automatically, calling the videotext of customers, and so on.

(12) All related complaint information are recorded in the CM database and repository.

We can design an integrated multi-channel collection routeway based on the CTI technique. The CTI service process is extended as shown in Figure 4. 


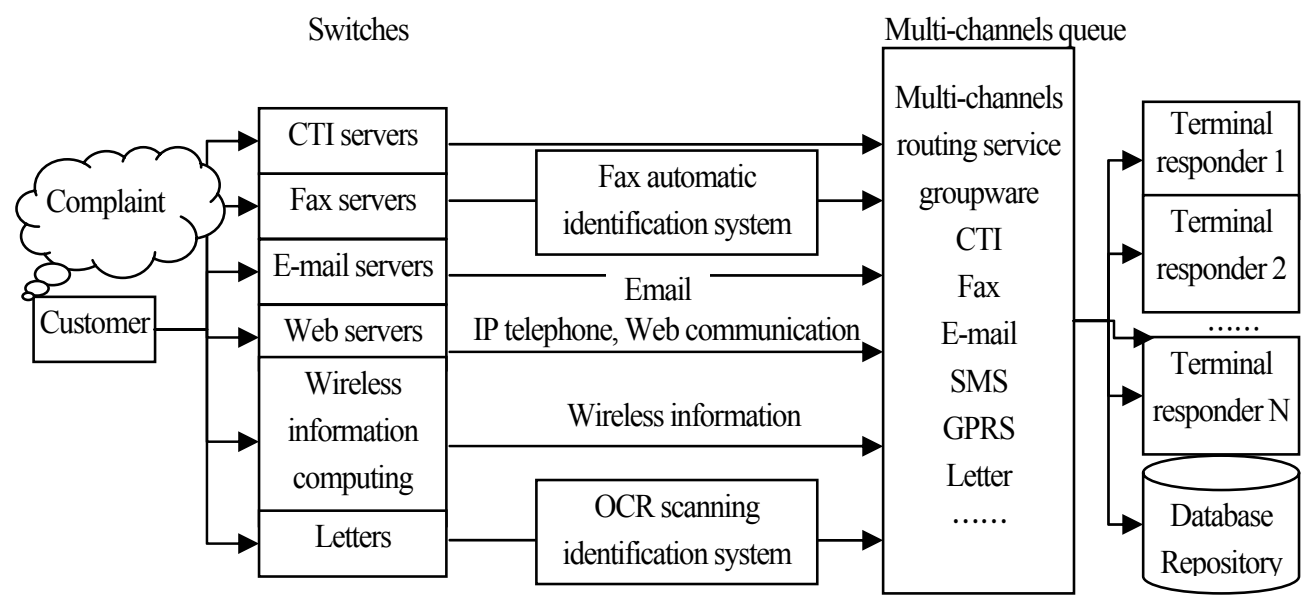

Figure 4. The integrated multi-channels collection routeway in $\mathrm{CM}$

The details of every process in the Figure 3 above are similar as the CTI service process; so there are no repeated expatiations. The complaint information via the integrated multi-channel in $\mathrm{CM}$ could achieve the $\mathrm{CM}$ processing system, which will be represented in detail in the next section.

\subsubsection{Evaluation}

\section{Production Inspection/Sort}

In this phase the returned products are sorted according to their current quality, spoilage degree, etc., after that it is the closed-loop supply chain turn to determine the reuse manner of the products and then classify them. Those products can be divided into no spoilage, partial spoilage, or complete spoilage and so on.

(i) No spoilage: The reverse flow that refers to products that are kept in the good state, then can often be reuse directly after using cleanout or quick maintaining easily.

(ii) Partial spoilage: The return products have been damaged partly, and need to be disassembled, inspected or tested, and repaired or replaced by parts, so their quality may be lowered. But, the products may be returned to customers, or be sold at a discount in the secondary market.

(iii) Complete spoilage: The returned products are damaged or deteriorated badly, though they may include valuable components, but that can be reused restrictedly. So the enterprises in closed-loop supply chain just carry out recycling, remanufacturing or harmless processing.

\section{Complaint Classification}

Customer complaints can be expressed different information according to the diversities of customer preference, the kinds of products etc. Therefore, enterprises in closed-loop supply chain 
need to apply different processing techniques; it is necessary to first classify complaint information. Based on the customer response, the complaint information is split into three levels.

Level I: Customers feel the complaint is too inappreciable and do not want to express, such information is obtained often through questionnaires.

Level II: Customers have some tempered complaint or appeal, which they want to make known to enterprises in closed-loop supply chain. The integrated multi-channel collection rounteway in $\mathrm{CM}$ could be their right choices.

Level III: The customers are heavy-handed. When appealing to the enterprise in closed-loop supply chain, they take violent attitudes and insist on own viewpoints all along.

\section{Evaluated Conclusion}

The integration evaluation conclusions are determined by the comparison of customer complaint and product quality; it is the gist for CM. Different customers have different apperceptions of product and service utility. It is necessary for the closed-loop supply chain to discern the customer reaction based on the product spoilage degree, or the spoilage degrees based on the customer complaint levels in order to reply with the corresponding disposal countermeasure.

In modern times, the intelligent system is extensively applied to help increasingly in decisionmaking. The intelligent "experts" based on the database and data storage can respond customer complaint quickly. For higher complaint level, in order to respond customer complaint exactly, the database and data storage should integrate more comprehensive information about customers and products. Intelligent Decision Support System (IDSS) is the combination of Artificial Intelligence (AI) and Decision Support System (DSS), using Expert System (ES) technique to make the traditional DSS more humanized and flexible (W. Cheung, L.C. et al., 2005; K.N. Papamichail, \& S. French, 2005).

The framework of IDSS consists of three subsystems (3S), namely, inlaid Languages System (LS), Problems Processing System (PPS) and Knowledge Management System (KMS), namely $3 \mathrm{~S}$ system. Figure 5 presents the framework of IDSS model.

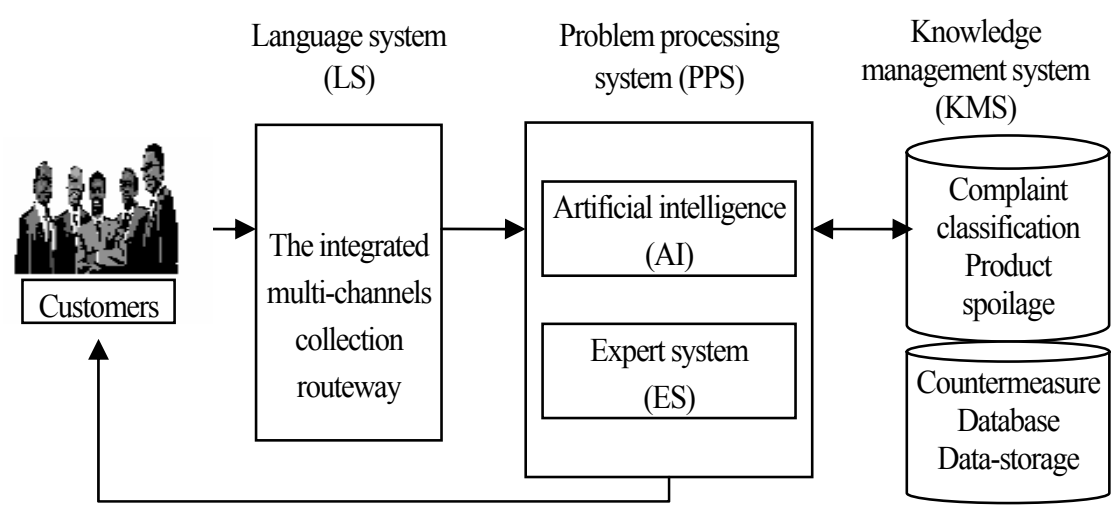

Figure 5. The framework of IDSS model 
There are some main advantages of IDSS: first, it is the synthesis of AI techniques, mathematics methods and decision approaches, i.e., the integration of knowledge management and mathematical deductions to provide strong support to decision-making; second, it using the thoughts of ES and Knowledge Management engineering (KME) to implement uniform preparation, uniform management, uniform control etc.; third, it makes full use of experts' knowledge, experience, judgment and decision-making cases. Consequently, the evaluation processing for CM in closed-loop supply chain will be supported by IDSS effectively.

\subsubsection{Disposal}

\subsubsection{Disposal countermeasures}

The disposal countermeasures of CM are presented in Table 1.

Table 1

The disposal countermeasures of $\mathrm{CM}$

\begin{tabular}{c|l|l|l}
\hline & \multicolumn{1}{|c|}{ Complaint on Level I } & Complaint on Level II & \multicolumn{1}{c}{ Complaint on Level III } \\
\hline \hline $\begin{array}{c}\text { No } \\
\text { spoilage }\end{array}$ & - & $\begin{array}{l}\text { Explain carefully; } \\
\text { Good service }\end{array}$ & $\begin{array}{l}\text { Replace by new products; } \\
\text { Resell the returned ones at a } \\
\text { discount or in a secondary } \\
\text { market }\end{array}$ \\
\hline $\begin{array}{c}\text { Partial } \\
\text { spoilage } \\
\text { Reclaim the products in lower } \\
\text { price; } \\
\text { Sales promotion; } \\
\text { Resell the return ones at a } \\
\text { discount or in a secondary } \\
\text { market after being repaired }\end{array}$ & $\begin{array}{l}\text { Give the returned ones } \\
\text { back to the customers after } \\
\text { being repaired }\end{array}$ & $\begin{array}{l}\text { Replace by new products; } \\
\text { Resell the returned ones at a } \\
\text { discount or in a secondary } \\
\text { market after being repaired }\end{array}$ \\
\hline $\begin{array}{c}\text { Complete } \\
\text { spoilage }\end{array}$ & $\begin{array}{l}\text { Reclaim the products free; } \\
\text { Recycle, remanufacture, or } \\
\text { dispose the returned ones } \\
\text { harmlessly }\end{array}$ & $\begin{array}{l}\text { Replace by inferior } \\
\text { products; } \\
\text { Recycle, remanufacture, } \\
\text { or dispose the returned } \\
\text { ones harmlessly }\end{array}$ & $\begin{array}{l}\text { Replace by new products; } \\
\text { Resell the returned ones at a } \\
\text { discount or in a secondary } \\
\text { market after being recycling, } \\
\text { remanufacturing, or harmless } \\
\text { disposal; } \\
\text { A compensation perhaps }\end{array}$ \\
\hline
\end{tabular}

\subsubsection{Utility of $C M$}

Customers' responses to the spoiled product show the expectation of the purchased products, so the utility of $\mathrm{CM}$ in closed-loop supply chain reflecting the customer expectation can be 
measured by two factors, i.e., the degree of product spoilage and the level of customer complaint. The more serious complaint means higher customer's expectation, here the utility of CM in closedloop supply chain will be greater. The lower expectation of customer may be easy to satisfy, so the utility of CM will not be great anymore. It is obvious that the utility of CM in the closed-loop supply chain have inverse ratio with the spoilage degree, and direct ratio with the complaint level.

Suppose that $\alpha$ and $\beta$ denotes the spoilage degree and the customer complaint level, respectively. $\gamma$ is used to express the utility of CM, namely, $\gamma=\beta / \alpha$.

Let us see the slanting diagonal in Table 1, the value of $\gamma$ equals or approaches 1 in the conditions of No spoilage-Complaint on Level I, Partial spoilage-Complaint on Level II, Complete spoilage-Complaint on Level III. These show the well-balanced utility of CM in the closed-loop supply chain. Compartmentalize the table into two parts according to this diagonal, the value is $\gamma>1$ in the top-right. Here the customers have high product expectation; CM in the closed-loop supply chain is significant and implies a great utility. In the lower-left of the diagonal, $\gamma<1$ means the low customer expectation. To enhance the utility of $\mathrm{CM}$ and increase the customer satisfaction in the closed-loop supply chain, the product design and marketing should be taken into consideration.

\subsubsection{The CM processing system}

By receiving complaint information and inspecting the products, the experts in closed-loop supply chain would give a reasonable disposal countermeasure.

When the level of customer complaint is lower and the product spoilage is not bad, the feedback can be disposed in the place of distributors, such as the wholesaler and the retailers. Especially, the retailers that keep in touch with the customers directly are the chief and basic nodes for CM in the closed-loop supply chain. For the complaint on Level I, good customer service is necessary along with the drumbeating in the right time. To satisfy the customer complaint on Level II and Level III, a lot of different means should be chosen according to the product status, for instance, recycle the products at a discount, replaced by new products, and so on. Then the return products can be resold in a secondary market after being repaired.

If the products are broken or even damaged badly, they should be transported to the manufacturer at short notice. The professional processing of manufacturers in closed-loop supply chain is significant for customer satisfaction. In other words, there is corresponding process for CM processing system in closed-loop supply chain as shown in Figure 6(V.D.R. Guide Jr, et al., 2003). 


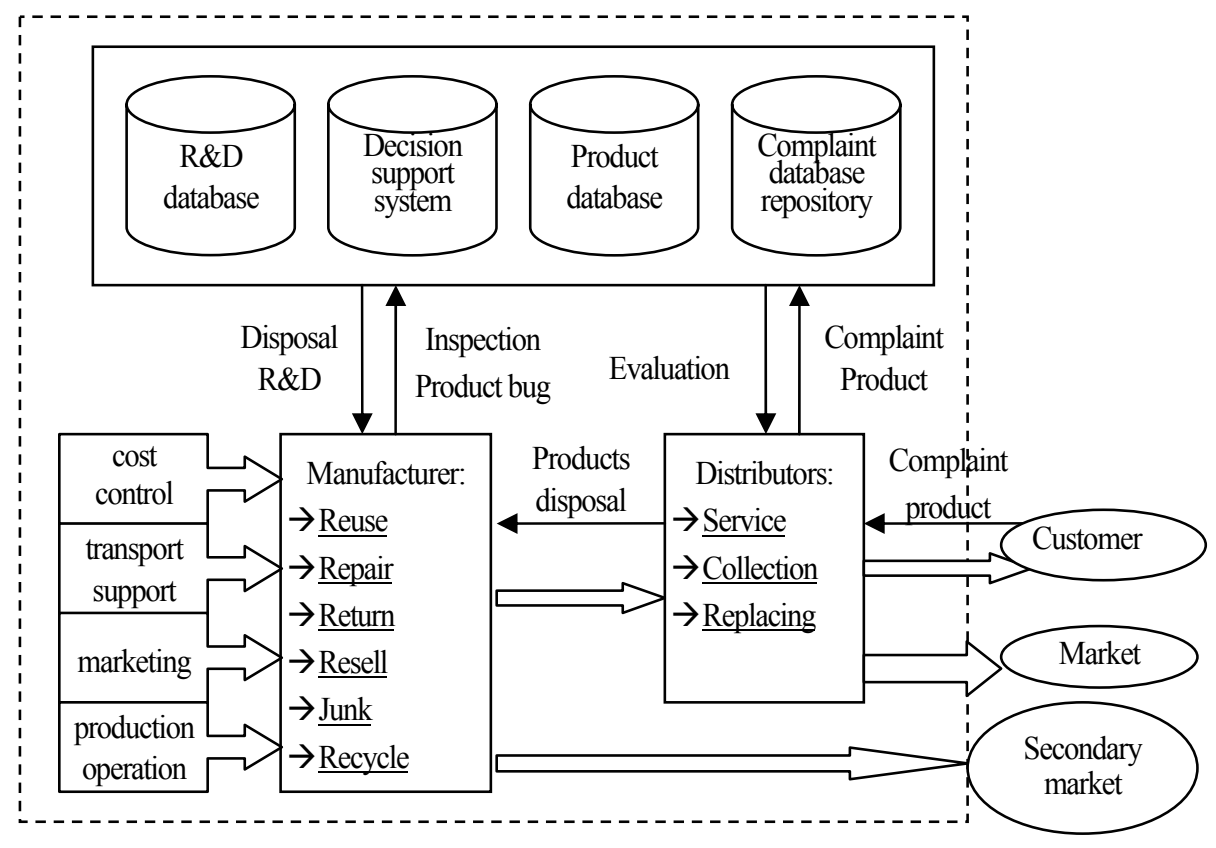

Figure 6. The CM processing system

The CM processing system in allusion to different disposal countermeasures is supported by the embedded information system; the real-time information exchange helps to provide the decision-making with support and improve the manufacture technique. Furthermore, the functions of the CM processing system is controlled and supervised by related function modules, such as cost control, transport support, channel management, marketing, production operation etc., to help the closed-loop supply chain construct the resources for an economized and harmonious system.

\section{Closed-loop supply chain under the circumstance of exergoeconomics}

\subsection{Systems thinking}

With regard to supply chain management, systems-thinking has influenced the discipline by 'thinking of the whole', rather than of individual aspects (Ibrahim Dincer, and Marc A. Rosen, 2004). This can be interpreted in two different ways. On the one hand, specific functional areas within one organization should not be seen in separation from the other functional areas in the same organization. On the other hand, it may be argued that a system approach aims to understand the whole supply chain and the interaction of the supply chain echelons, rather than focusing on one organization only. General systems theory, however, is not only concerned with how an 
organization operates, but it also seeks to investigate the interaction between an organization and its environment. A distinction can therefore be made between open and closed systems.

Closed systems operate independently from the environment and without outside influence; open systems describe an interaction between the organization and the outside world (Hodge, B. J. and Anthony, W. P., 1991). These definitions are observed systems that interacted with their environments and therefore called them 'open systems'. System theory is relevant to closed-loop supply chain management for two reasons.

Firstly, it shares common roots with industrial ecology theory. Allenby (1999) argues that the understanding of complex economic systems is an essential element of industrial ecology. In addition, industrial ecology applies tools that are similar to the methods used within research that takes a systems perspective (input-output models; systems modeling). The critical need for a systems perspective within industrial ecology is also emphasized by Lifset, R. and Graedel, T. E. (2002). In their eyes, systems thinking can be found within industrial ecology due to the life cycle perspective that is adopted and the material and energy flow analyses that are applied. Definitions of the term industrial ecology refer to a 'systems view', 'industrial systems' as well as 'surrounding systems' and the optimization of resources, energy or capital. Moreover, both theoretical perspectives incorporate elements of 'efficiency' and 'optimization', with regard to materials, capital, energy or processes.

\subsection{Exergy thinking}

Exergy is defined as the maximum amount of work which can be produced by a system or a flow of matter or energy as it comes to equilibrium with a reference environment. With the quantity of energy, exergy deals with both quantity and quality of energy. The combination of exergy analysis and economics is represented by exergoeconomics.

A closed-loop supply chain system can be simple activities as follows: Resources (labor, cash, material, etc.) and energy (information, technology, etc.) are the inputs and products, wastes (excess material, defect, etc.) and waste energy are the outputs of the system. Some of the outputs can be reused, such as excess materials, but others are turned into real wastes and cannot be used again. Therefore, resource utilization and the environmental impact make up of the sustainability of a closed-loop supply chain system and become the key performance indicators. The environmental impact can be decreased using by increasing of the exergy efficiency of a closed-loop supply chain system based on the three factors as follows (Xin Xie, and Guojun Ji, 2006):

(1) Order destruction and chaos emergence. The components of closed-loop supply chain are scattered geographically. It is easy to see the closed-loop supply chain become chaotic and it is hard to find out the causes based on the complexity theory. For example, the existing uncertainties result in the difficulty in operating closed-loop supply chain, result in these enterprises in the chain often neglect the reverse activities. In fact, the more destructed the closed-loop supply chain system is, the lower the exergy efficiency is, and the worse the performance is.

(2) Resource degradation. Three main factors can result in resource degradation: damaging 
composition of the used resource, harmful pervasion from the reactivity of the used resources and the defects damaging to the society or human life. The principal general technique that is applied to reduce the environmental impact is green design, which takes the environmental factors and economy rationality into consideration, to improve the exergy efficiency and minimize the exergy losses of every process in the whole product life cycle thus lowering the environmental impact.

(3) Waste exergy emissions. The exergy of the wastes is a consequence of not being in stable equilibrium with the environment and represents a potential change. Usually, emitted exergy causes a change, which may be damaging to the environment, such as radiation harmfulness on human health caused by mobile phones, although in some cases the change may be perceived to be beneficial (e.g. the achievement of closed loop for the whole product life cycle).

Based on exergoeconomics, the closed-loop supply chain is regarded as a closed-loop energy system and its exergy losses involve two portions: the relative wasters release exergy losses from the closed-loop supply chain (exergy losses on account of release) and the no-reverse process results in the interior exergy losses (interior wasting losses). Two parts summation is exergy losses $L_{e x}$ of the system $L_{e x}$, i.e., $L_{e x}=$ release exergy losses + interior wasting exergy losses

Now, considering that the whole financing cost is $K$ in closed-loop supply chain, which expenses incurred in activities included in procured materials to distributed products, to deliver to customers, even return, recycling relative to logistics etc., this cost can be classified parts for input cost, output cost and closed-loop supply chain cost. Where the input cost comes from production activities relative to procurement, manufacture and so on, such as the operation cost incurred in procuring parts, facilities, labors etc; the output cost is relative to expense appearing in final output activities, such as the movement cost incurred in distribution, after service and transport etc.; the reverse logistics cost appearing in return processing, involving in the movement cost incurred in reuse, repair, regeneration, recycle, remanufacturing etc. Therefore, $K=$ input cost + output cost + reverse logistics cost.

To discuss the relationship between economical benefit and exergy losses in closed-loop supply chain, we introduce a new parameter $R_{e x}$, it is defined as a ratio of exergy losses accounting for total financing cost, i.e., $R_{e x}$ describes that the unit financing cost corresponding to the exergy losses of system, to estimate the exergy losses of system from point of economy, and evaluate the economical benefit of system from point of energy, so $R_{e x}=\frac{L_{e x}}{K}$.

In the closed-loop supply chain, there is only one optimat value $R_{e x}^{*}$, and economical benefit produced by the system exergy while $R_{e x}=R_{e x}^{*}$. Amount of $R_{e x}^{*}$ is determined by environmental change, such as strategy, technology, time, resources and information. Commonly, based on given financing support, the exergy losses produced by higher technological-level suppliers are less than the lower-level suppliers in closed-loop supply chain, and the preceding economical value is higher than the latter, so different in $R_{e x}^{*}$. At the same time, in market economy, price of materials will fluctuate with change of supply and demand, inflation etc., thus result in continual change of financing cost, even if exergy losses are similar, $R_{e x}^{*}$ will be equivalent in different periods. All costs change follow the exergy losses of closed-loop supply chain as represented in Figure 7. 
In Figure 7, all lines $L$ started from $\mathrm{O}$ is set of $R_{e x}=R_{e x}^{*}$, curve $N$ denotes the relationship between $L_{e x}$ and $K$, which reflects the trade-off in cost and benefit; for example, increasing investment can cut down exergy losses. It is easy to see, if there are any investment in the closedloop supply chain, i.e., $K=0$, then all input exergy is wasted, and exergy losses $L_{e x}$ reach the maximal value; if there are quite larger investment in the closed-loop supply chain, then almost all exergy losses are avoided or eliminated, and performance will be close to the ideal result, i.e., for $K \rightarrow \infty$. In the point of intersection $A$ for curve $N$ and line $L, R_{e x}=R_{e x}^{*}$ holds, this means the system reaches the optimal trade-off between investment and exergy losses; such point is our expectation. Considering that the upper points of $A$ for the curve, those will show $R_{e x}>R_{e x}^{*}$, which indicates that the lesser investment, the higher exergy losses in closed-loop supply chain, and resources of the system are not utilized sufficiently, hence, increasing investment and decreasing losses, such that $R_{e x}$ approaches to the equilibrium point $A$. Under the points of $A$ for the curve, those will show $R_{e x}$ $<R_{e x}^{*}$, which indicates that the higher investment, although lower exergy results in great losses, such strategies are not unreasonable, since any system cannot pay the large amounts of fund, the right investment, such that trade-off points for exergy losses and investment tend towards $A$.

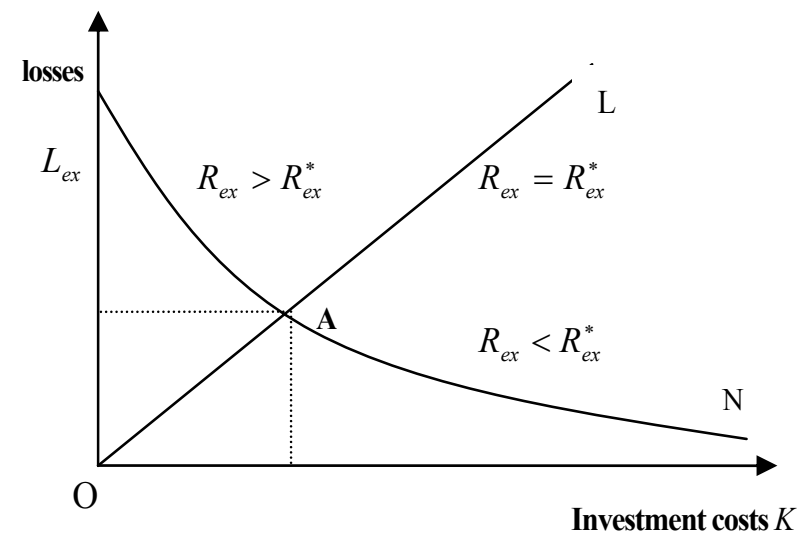

Figure 7. Relationship between exergy losses and investment costs

The objective of philosophy for constructing the closed-loop supply chain is to minimize resources losses and maximize financing utilization. Every successful supply chain system lays siege to an optimal $R_{e x}^{*}$, the not good operating system will be far off the corresponding $R_{e x}^{*}$. Therefore, managers must adopt all kinds of measures to reduce the gap between $R_{e x}$ and $R_{e x}^{*}$, and reach the equilibrium between exergy losses and investment of system. The closed-loop supply chain management continually adjusts the proportion between exergy losses and investment of system to approach the state of $R_{e x}=R_{e x}^{*}$ gradually, hence maximizes the whole performance.

In short, exergy constrained in a closed-loop supply chain system represents a resource, while exergy emitted to the environment becomes unconstrained and represents a driving potential for the 
environment. Therefore, reverse logistics, as the main functional department to lower environmental impact of the closed-loop supply chain system, can be defined in the view of exergy as the process changing the unconstrained exergy emitted out of the closed-loop supply chain system into constrained exergy through the procedures of collection, inspection/sort and reprocessing and controlling the increasing trend of the potential to change the environment.

The sustainable development of a closed-loop supply chain system means the development that meets the demands of the present customers without compromising the ability of future customers to meet their own demands. Indeed, energy production and consumption result in significant environmental problems and expenses that can have serious consequences and even exist in some risks to the long-term sustainability of the closed-loop supply chain system. Sustainability of a closed-loop supply chain system requires not just sustainable energy resources, but the resources need to be used efficiently. Exergy is a measurement of the quality of energy, and quantifies the degradation of material in the closed-loop supply chain system. Since it enables us to find the locations, types, and true magnitudes of wastes and losses, applying exergy analysis to a component, process or sector in the closed-loop supply chain system can lead to insights on improving the sustainability of the activities comprising the system by decreasing exergy losses. Impact associated with emissions and resource depletion can be represented in terms of one exergy-based indicator, such as exergy efficiency. Sustainability of the closed-loop supply chain system is regarded as environmental impact to decrease the exergy efficiency of the system. When exergy efficiency approaches $100 \%$, environmental impact approaches zero, since exergy is only converted from resources to products without loss. Also sustainability approaches infinity because the closed-loop supply chain system approaches reversibility (exergy can also be converted from products to resources). When exergy efficiency approaches $0 \%$, sustainability approaches zero because exergy containing resources are used but no product appears. Also, environmental impact approaches infinity because an increasing quantity of resources is needed and a correspondingly increasing amount of exergy wastes are emitted from the closed-loop supply chain system.

\section{Model introduced}

In this section, we will introduce the performance model based on exergoeconomics. Firstly, the exergy analysis is extended to take the environmental impacts of closed-loop supply chain system into consideration. The closed-loop supply chain system influences the environment because of the waste discharged by it, which includes two parts: one is from the emitted heat; the other is the physical exergy and chemical exergy of the waste itself. However, the various components in the wastes, with different chemical nature, bring different harm to the environment. Here, a damaging feature be denoted by the negative environmental effect $(E N E)$ is defined $E N E=\sum B_{i} E_{x, i}$, where $E_{x, i}$ denotes the physical and chemical exergy of the component $i$ in the system's wastes; and $B_{i}$ is the harm coefficient of component $i$ to the environment.

Secondly, the exergy analysis can be extended to assess the comprehensive effect of the closed-loop supply chain system considering resource and environmental impact. So, while dealing 
with the total effect of the closed-loop supply chain system, the exergy discharge loss should be considered twice, resource waste in the total exergy loss of the system, and impact on the environment in the ENE. However, the resource waste and the environment pollution can not be considered as equal, so the effect coefficient is introduced for use here. The system negative effect $(S N E)$ is defined as $S N E=C_{1} E_{x l, t o t}+C_{2} E N E$, where, $E_{x l, t o t}$ is the total exergy loss of the system; $C_{1}$ and $C_{2}$ are the effect coefficients. It is difficult to determine the effect coefficient of the system's negative effect, since resource waste cannot be compared with environmental pollution in a direct way. To solve this problem, the economic losses often are used to determine the effect coefficients. Let the exergy loss of the system be represented as $E_{x L}=\Delta M+\Delta P+R$, where $\Delta M$ is the material loss of the system, $\Delta P$ is the product loss of the system, and $R$ denotes the residual of the system. Then the economic loss caused can be calculated by the equation $E_{e L}=\sum E_{x L} P_{i n}$, where $P_{\text {in }}$ denotes the average input exergy cost of the system.

$S N E$ is an absolute variable, which can be used to evaluate different models of the systems with the same type or different designed systems, but cannot be used to evaluate the different types systems. So a relative variable $S N E F$ is defined as $S N E F=\frac{S N E}{E_{x, i n}}$, where, $S N E F$ is factor of $S N E$, and $E_{x, i n}$ denotes the system's input exergy.

\section{Case study}

We consider that two cement closed-loop supply chain systems selected from 18 manufacturers in China, A and B, are as follows. The flow charts of system A and B are shown in Figure 8. Based on exergoeconomics and in view of the resource utilization and environmental impact, the calculation and analysis of the sustainability of the abovementioned cement closed-loop supply chain systems performance is considered as follows.

(1) Calculate the input exergy, the output exergy, the whole system exergy and the physical and chemical exergy of all wastes in these two closed-loop supply chain systems. Since the harm coefficients are hard to determined, we use the emissions limit for secondary standard in Cement Factory Atmosphere Emissions Standard constituted by China Environment Protection Department (GB 4915-1996) as the harm coefficients. So the environmental negative effect in supply chain system $\mathrm{A}$ is $E N E=0.00006 \times 10^{6} \times 0.9+21.1318 \times 10^{6} \times$ $1.0+0.00006 \times 10^{6} \times 2.4 \times 0.2376 \times 10^{6} \times 0.03=2.12 \times 10^{7} \mathrm{kj} / T$ And that in system $\mathrm{B}$ is $E N E=$ $4.57 \times 10^{6} \mathrm{kj} / T$. 

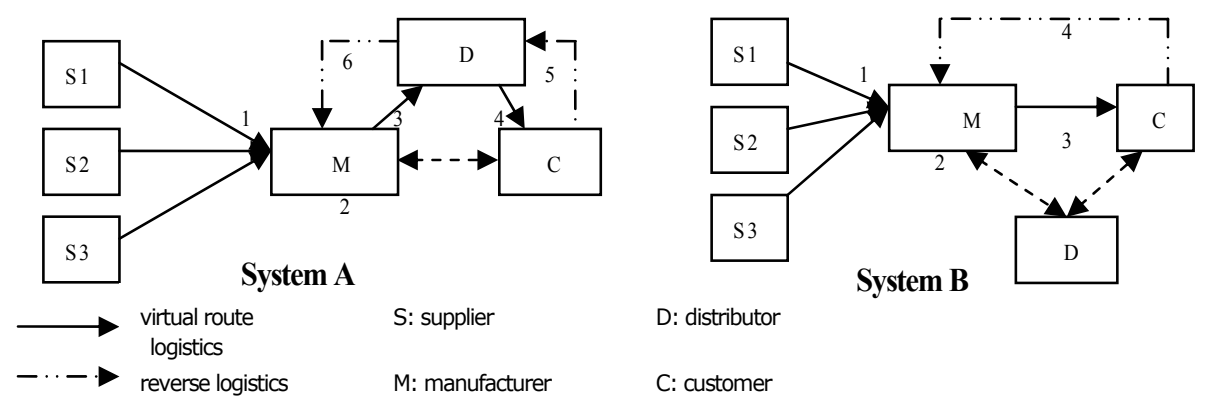

Figure 8. Flow charts of cement closed-loop supply chain systems A and B

(2) Calculate the economic loss caused by resource waste. It can be deduced by the average input exergy cost of a system multiplying the total exergy loss of the system. So the economic losses of resource waste in system A is $1,590,800 ¥ / \mathrm{a}$, and that in system B is $1,538,000 ¥ / \mathrm{a}$.

(3) Calculate the economic loss of environmental impact which caused mainly by the powdery dust, $\mathrm{CO}_{2}, \mathrm{SO}_{2}$ and other oxides emitted from the cement closed-loop supply chain system. It can be divided into two parts, one is the influence on the natural environment and the other is on human health. It is hard to quantify the economic loss of the natural environment caused by the system. To some extent, the pollutant penalties are established by the Environment Protection Departments, the processing cost to handle the contamination in the factories, cost of dust catcher and cloth for enveloping the powdery dust on trucks can reflect the approximate costs, so we can use the sum of these to denote the economic loss of environment effect in cement system A is 222,000¥/a, and that in system B is 191,000¥/a.

The economic loss caused by the influence on human health can be calculated by the sum of direct and indirect economic loss. Cement powdery dust is a kind of harmful substances. Once one inhales it, specific amounts can result in diseases, such as lung disease, and it deteriorates the working ambience. Direct economic loss includes medical cost, income loss and cost of dust protection measures for workers. Indirect economic loss comprises economic loss based on work delay and food pollution. Therefore, the economic loss of human health caused by both cement closed-loop supply chain systems is $24,710 ¥ / a$. And then we can calculate the total economic loss of the cement supply chain system A is $249,410 ¥ / \mathrm{a}$, and that of system B is about $215,710 ¥ / \mathrm{a}$.

(4) So, we can calculate that for system A, $S N E$ is 2.888 and $S N E F$ is 0.0174 ; for system B, $S N E$ is 0.272 and $S N E F$ is 0.0016 .

The calculation process and results show that the system's negative effect factor can finally evaluate the resource utilization and environmental influence in the closed-loop supply chain system, which are the two key aspects of the sustainability and can be used as an objective to 
further optimize the closed-loop supply chain. The results show a less effect coefficient of environment negative effect. This is because the method effect coefficient is calculated by economic loss. In the present system of price and pollution penalty, the resource waste plays a primary role in system negative effect. But with the increasing recognition of the environmental protection, much restricting criteria of contamination discharge will be issued. Besides, the need for closed-loop supply chain forces companies to think more of the reverse logistics. If it cannot be responsible for the whole product life cycle, a company will be punished or even excluded from the marketplace. Therefore, the proportion of the influence to the environment will rise as well.

It can be seen from the results that the main contamination released by the cement supply chain system is cement powdery dust. So the system should be improved by reducing the emission of powdery dust; for example, utilizing advanced dust catcher and regulations for envelopment of the trucks and route or time period for the loading trucks. The negative effect coefficient of cement closed-loop supply chain system B is much less than that of system A; this means that system B is much better than system $A$ in sustainability. It is easy to see that cement flow in system A is more complicated than that in system B, thus resource waste increases and environment aggravates. In fact, according to reported in Chinese News, there are released amounts more than two cement factories annually. Therefore, sustainability of the closed-loop supply chain system decreases and system performance gets worse.

In fact, from post-1990, the global resources limitation, execrable environment, market demand to lower costs, amity with environment and social sustainability principles etc., those awake our organizations in closed-loop supply chain to readjust their operation system, such as create a values-based organization, adapt and thrive with environment all around, use a new language for success, develop vital flows and relationships with instantaneously, merge art and science and future, learn from natural systems, put community back in business and so on. Therefore, enterprises in the closed-loop supply chain must setup the symbiosis, for example, the enterprises must operate together, the enterprises must be situated near each other, for symbiosis to work, and must be reasonable near each other, openness between the enterprises. In a word, a good closed-loop supply chain management, theoretical and practical results have given our clear answer: openness, communication, mutual trust and amity with environment and social sustainability principles.

\section{Conclusion}

The complaint service management, aim at improving the customer satisfaction, is an important content for closed-loop supply chain. By analyzing the relationships between complaint management and closed-loop supply chain in this paper, CM in the closed-loop supply chain is probed into. Along with the rapid development of art and science, it is necessary and required to enable these advanced technologies to help CM perform more efficiently and effectively. In this paper, we take into consideration the process computing of $\mathrm{CM}$ by combing the computer, the communication and the information technologies. Based on the computer telephone integration 
technology, an integration multi-channel collection routeway can be designed; the evaluation of complaint and production is supported by intelligent decision support system. In accord with the different disposal countermeasures, the CM processing system is established to implement corresponding disposal, which reflects the utility of $\mathrm{CM}$. Based on the exergoeconomics methodology and the closed-loop supply chain management theory, the resource utilization and the environmental impact of the sustainability of closed-loop supply chain system is proposed systematically. Case studies show that the method widens the application range of the exergoeconomics methodology to evaluate closed-loop supply chain system performance and gives us a new insight into the closed-loop supply chain management. Finally, exergoeconomics can be helpful in finding out the weak link of the closed-loop supply chain system and show us how to improve the system performance.

\section{Acknowledgement}

This work is supported by the Program for New Century Excellent Talents in Fujian Education Department.

\section{References}

Allenby, B. R. 1999. Industrial ecology: policy framework and implementation. New Jersey: Prentice-Hall.

Andreasen A.R. 1988. Consumer-Complains and Redress: What we know and what we don't know in the frontier of research in the consumer interest. American council on consumer interests. (4): 675-722.

Cheung, W., L.C. Leung and C.F. Tam Philip. 2005. An intelligent decision support system for service network planning. Decision Support Systems. 39 (3): 415-428.

Chouinard, M., D'Amours Sophie and Aït-Kadi Daoud. 2005. Integration of reverse logistics activities within a supply chain information system. Computers in Industry. 56 (1): 105-124.

Cruz, M. 2000. Take it back: reverse supply chain companies meet demand. Computer Reseller News. Jun 52000 (897): 3.

Guide, V.D.R. and L. N. Van Wassenhove. 2003. Business aspects of closed-loop supply chains. In: V.D.R. Guide and L.N. Van Wassenhove eds. Business aspects of closed-loop supply chains: exploring the issues. Pittsburgh, Pennsylvania: Carnegie Bosch Institute. 17-42.

Guide Jr, V.D.R., V. Jayaraman and J.D. Linton. 2003. Building contingency planning for closedloop supply chains with product recovery. Journal of Operations Management. 21 (3): 
259-279.

Hodge, B. J. and W. P. Anthony. 1991. Organization theory: a strategic approach. Fourth Edition. Needham Heights. Massachusetts: Allyn and Bacon.

Ibrahim Dincer and Marc A. Rosen. 2004. Thermodynamic aspects of renewables and sustainable development. Renewable and Sustainable Energy Reviews. 9:169-189.

Ji, Guojun. 2006. Market-motivated value systems, reverse logistics and the evaluation model for the third party reverse logistics providers. Journal of International Logistics and Trade. 4 (1): 53-92.

Krikke, H. R. et al. 2003. Concurrent product and closed-loop supply chain design with an application to refrigerators. International Journal of Production Research. 41(16): 3689-3719.

Lifset, R. and T. E. Graedel. 2002. Industrial ecology: goals and definitions. In: R.U. Ayres and L.W. Ayres eds. A Handbook of Industrial Ecology. Cheltenham: Edward Elgar Publishing. 3-15.

Marisa, P. de Brito and R. Dekker. 2002. Reverse logistics-a framework. Econometric Institute Report EI. 38.

Morrell, A. L. 2001. The forgotten child to the supply chain. Modern Materials Handling. 56(6): 33-36.

Papamichail, K.N. and S. French. 2005. Design and evaluation of an intelligent decision support system for nuclear emergencies. Decision Support Systems. 41 (1): 84-111.

Rogers, D. S. and R.S. Tibben-Lembke. 2001. An examination of reverse logistics practices. Journal of Business Logistics. 22 (2): 129-148.

Shang, X.Y. and Guojun Ji. 2006. An applying research on CRM's complaints management under new information technology. Technology Development of Enterprise. 25 (3): 55-58.

Shizhen, Bai et al. 2005. Application of exergoeconomics in supply chain management. Logistics Technology. 10: 1-2.

Smith, V. M. and G. A. Keoleian. 2004. The value of remanufactured engines. Journal of Industrial Ecology. 8(1-2): 193-221.

Thierry, M. et al. 1995. Strategic issues in product recovery management. California Management Review. 37(2): 114-137.

Xin, Xie and Guojun Ji. 2006. Supply chain system performance evaluation by using exergoeconomics. Proceedings of the 11th International Symposium on Logistics. 2006 Beijing. 197-202.

Yanfeng W. and F. Xiao. 2001. Exergy analysis involving resource utilization and environmental influence. Science in China (Series B). 1: 86-95.

You, J.X., X.M. Du and Y. Wang. 2003. Customer Complaint Management. Beijing: Petroleum Industry Press. 